\title{
Occurrence, fate and risk assessment of parabens and their chlorinated derivatives in an advanced wastewater treatment plant
}

\author{
Wenhui $\mathrm{Li}^{\mathrm{a}}$, Yali Shi ${ }^{\mathrm{b}}$, Lihong Gao ${ }^{\mathrm{a}}$, Jiemin Liu $^{\mathrm{a}, * *}$, Yaqi Cai ${ }^{\mathrm{b}, *}$ \\ a School of Chemistry and Biological Engineering, University of Science and Technology Beijing, University of Science and Technology Beijing, Beijing \\ 100083, China \\ b State Key Laboratory of Environmental Chemistry and Ecotoxicology, Research Center for Eco-Environmental Science, Chinese Academy of Sciences, \\ Beijing 100085, China
}

\section{H I G H L I G H T S}

- Parabens are ubiquitous in aqueous and sludge samples in WWTP.

- Octylparaben with longer chain was firstly detected in this study.

- Chlorinated parabens are more stable than their parent compounds through advance treatment.

- The risks of target compounds are negligible at environmentally relevant levels.

\section{A R T I C L E I N F O}

\section{Article history:}

Received 22 April 2015

Received in revised form 23 June 2015

Accepted 24 June 2015

Available online 27 June 2015

\section{Keywords:}

Parabens

Chlorinated parabens

PHBA

Advanced wastewater treatment plant

Risk assessment

\begin{abstract}
A B S T R A C T
In the present study, parabens, $p$-hydroxybenzoic acid (PHBA) and chlorinated derivatives, were simultaneously determined in wastewater and sludge samples along the whole process in an advanced wastewater treatment plant (WWTP). Nine target compounds were detected in this WWTP, and methylparaben and PHBA were the dominant compounds in these samples. It is noteworthy that octylparaben with longer chain was firstly detected in this work. Mass balance results showed that $91.8 \%$ of the initial parabens mass loading was lost mainly due to degradation, while the contribution of sorption and output of primary and excess sludge was much less (7.5\%), indicating that biodegradation played a significant role in the removal of parabens during the conventional treatment process. Specifically, parabens were mainly degraded in the anaerobic tank, and PHBA could be effectively removed at high rates after the advanced treatment. However, both biodegradation and adsorption accounted for minor contribution to the removal of chlorinated parabens during conventional treatment process, and they were only scantly removed by conventional treatment (33.9-40.7\%) and partially removed by advanced treatment (59.2-82.8\%). Risk assessment indicated that parabens and their chlorinated derivatives in second and tertiary effluent are not likely to produce biological effects on aquatic ecosystems.
\end{abstract}

(c) 2015 Elsevier B.V. All rights reserved.

\section{Introduction}

Parabens, a group of alkyl esters of the $p$-hydroxybenzoic acid (PHBA), are extensively applied as antimicrobial preservatives in food commodities, industrial products, pharmaceutical and personal care products [1-3]. Due to their ongoing wide use and continuous introduction into the environment through domestic and industrial wastewater, parabens have been recently found in

\footnotetext{
* Corresponding author. Fax: +86 1062849182.

** Corresponding author.

E-mail addresses: liujm@ustb.edu.cn (J. Liu), caiyaqi@rcees.ac.cn (Y. Cai).
}

water, soil, sediment, dust and fish [4-8]. As an emerging group of endocrine-disrupting chemicals, parabens have attracted growing attention due to their potential long-term effects on human health and aquatic organisms. Recently, the occurrence and transportation pathways of these compounds into the aquatic ecosystems have been receiving particular attention.

Wastewater treatment plants (WWTPs) are considered efficient in the removal and degradation of parabens [1,9]. Several studies have demonstrated that most of parabens in aqueous-phase were effectively removed during conventional sewage treatments in WWTPs, with the average removal rate over 90\% [10,11]. However, it is not clear whether the total input of parabens is really lost during the treatment, accumulates in sludge or ends up dis- 
charged with the effluent. Recently, most studies about the fate of parabens in WWTPs focused only on the aqueous phase, whereas concentrations of parabens in sludge and their removal during the whole treatment process were rarely investigated. In the limited studies, some parabens were found in sewage sludge samples at relatively high levels [12,13], indicating that some parabens may be removed by sorption and transported to sludge during sewage treatment. In order to distinguish the specific removal processes of WWTPs whether they were degraded to their degradation products or only physically sequestrated by sludge, the occurrence and fate of parabens in both wastewater and sludge should be emphasized. In addition, although quite high removal efficiencies of parabens have been achieved during conventional treatments, some of them are still frequently found in secondary effluent and receiving surface waters $[4,10]$. Owing to the lack of information on the removal of parabens during advanced treatments, it is required to assess whether the additional process, such as advanced oxidation and membrane separation, can further reduce the levels of parabens in the effluents of WWTPs. Considering the fact that several parabens are slightly toxic to aquatic invertebrates and fish [14,15], the assessment for the potential environmental risk of these parabens to the aquatic ecosystems is warranted.

Besides the common parabens in previous studies, octylparaben (OcP), PHBA, and chlorinated parabens were also selected as target compounds in this study. Although OcP was not included in previous studies, it is used as a preservative in high-quality cosmetics and pharmaceuticals. Various published studies have reported that parabens with longer linear chains are generally more potent than those with shorter chains, and their persistence seems to increase with the length of the alkyl chain $[16,17]$. Considering the structure of target parabens, OcP with the longest chains showed the strongest estrogenic activity and persistence in the environment [18]. It is reported that removal of the ester group from parabens does not eliminate their estrogenic activity, and their main metabolite product, PHBA, can also give estrogenic responses $[19,20]$. Therefore, PHBA can be still regarded as estrogenic, so its occurrence and fate should be included in future studies. Moreover, with the active phenolic hydroxyl groups, parabens can be easily transformed to chlorinated derivatives in chlorinated water [21], which are considerably more stable in environment and more toxic to aquatic organisms than the corresponding parent compounds $[1,22]$. To the best of our knowledge, there are only very scarce data available on the presence and levels of PHBA and chlorinated derivatives in the WWTPs [23].

In the present study, the occurrence and fate of 13 target compounds, including PHBA, 8 parabens, and 4 chlorinated derivatives, were simultaneously studied in wastewater and sludge samples along the whole sewage treatment process from an advanced wastewater treatment plant. The objectives of this study were to estimate the removal efficiencies of parabens during various treatment steps, to investigate the possible removal pathways of selected compounds in this WWTP, and to evaluate the risks of target parabens to aquatic organisms. The results will significantly help to understand the behavior and fate of parabens, PHBA, and their chlorinated derivatives in the typical WWTPs.

\section{Experimental}

\subsection{Reagents and standards}

All solvents were HPLC-grade and purchased from Fisher scientific (Pittsburgh, PA, USA); ammonium acetate (99\%) was purchased from Alfa Aesar; all purity water $\left(>18.2 \mathrm{M} \Omega \mathrm{cm}^{-1}\right)$ was prepared with Milli-Q Advantage A10 system (Millipore, Bedford, MA, USA).
Chemical standards of p-hydroxybenzoic acid (PHBA) Methylparaben (MeP), Ethylparaben (EtP), Propylparaben (PrP), Butylparaben (Bup), Pentylparaben (PeP), Heptylparaben (HeP), Benzylparaben (BzP), Octylparaben (OcP), Methyl 3-chloro-4-hydroxybenzoate (3-Cl-MeP), Methyl 3,5-dichloro-4-hydroxybenzoate (3,5-2Cl-MeP), Ethyl 3-chloro-4-hydroxybenzoate (3-Cl-EtP), and Ethyl 3,5-dichloro4-hydroxybenzoate (3,5-2Cl-EtP) were purchased from AccuStandard Inc. (New Haven, CT, USA).

The isotopically labelled compounds were used as surrogate standards $\left(500.0 \mu \mathrm{g} / \mathrm{L}\right.$ in methanol): $p$-hydroxybenzoic acid- $\mathrm{d}_{4}$ $\left(\right.$ PHBA- $\left.\mathrm{d}_{4}\right)$, Methylparaben- $\mathrm{d}_{4}\left(\mathrm{MeP}-\mathrm{d}_{4}\right)$, Ethylparaben- $\mathrm{d}_{5}($ EtP$\left.d_{5}\right)$, Propylparaben- $d_{7}\left(\right.$ PrP- $\left.d_{7}\right)$, Butylparaben- $d_{9}\left(B u P-d_{9}\right)$ and Benzylparaben- $\mathrm{d}_{9}\left(B z \mathrm{P}-\mathrm{d}_{7}\right)$, which were purchased from Toronto Research Chemicals (Oakville, ON, Canada). The physicochemical characteristics of target parabens are summarized in Table S1.

\subsection{Sample collection}

The advanced wastewater treatment plant located in Beijing was designed for approximately 810,000 inhabitants with an average domestic wastewater flow of $200,000 \mathrm{~m}^{3} /$ day. This facility consists of primary treatment, and a conventional activated sludge (CAS) system, coupled with a subsequent tertiary treatment system. Sewage is firstly passed through the screen and aerated grit chamber as the primary treatment. Then, the primary effluent flows through an activated sludge system (anaerobic, anoxic, and oxic tanks). After a secondary clarification step, most of the second effluent $\left(120,000 \mathrm{~m}^{3} / \mathrm{d}\right)$ is discharged into a receiving river, while the rest is treated by ultrafiltration and ozonization processes as the tertiary treatment. The tertiary effluent is used for landscape water and irrigation water.

The scheme of the WWTP and sampling locations are shown in Fig. 1. Four samplings were performed at the outlet of each treatment step in November 16, 2013, January 7, 2014, April 15, 2014, and July 14, 2014. Samples were collected as $24 \mathrm{~h}$ composite samples by using automatic samplers with sampling interval of $2 \mathrm{~h}$. All samples were taken at the outlet of every treatment step, and they were immediately centrifuged to separate into the aqueous phase (water) and solid phase (sludge) after sampling. Water samples were filtered through $0.45 \mu \mathrm{m}$ (Whatman, Maidstone, U.K.) nylon membrane prior to analysis. Sludge samples were lyophilized in a freeze-dryer, then ground and passed through a 55-mesh sieve, and stored at $-20^{\circ} \mathrm{C}$ until analysis.

\subsection{Sample preparation and chemical analysis}

Water samples were extracted by a solid phase extraction (SPE) method, as described in a previous study with some modifications [24]. Briefly, $20 \mathrm{ng}$ surrogate standards (PHBA-d $\mathrm{d}_{4}, \mathrm{MeP}-\mathrm{d}_{4}$, EtP- $d_{5}, P r P-d_{7}, B u P-d_{9}$ and $\left.B z P-d_{7}\right)$ were added to $500-m L$ filtered water samples, and then target compounds were extracted with the Oasis HLB cartridge using an AutoTrace SPE 280 system (Dionex, Sunnyvale, USA). Extracts were purified and concentrated before analyzing with LC-MS/MS. As for sludge, 0.1-g pretreated lyophilized sample was spiked with $20 \mathrm{ng}$ of surrogate standard, and then target compounds were extracted with an ASE 350 pressurized liquid extraction (PLE) system (Dionex, Sunnyvale, USA). The extract was concentrated to a final volume of about $1 \mathrm{~mL}$, and diluted to $100 \mathrm{~mL}$ with purity water. SPE procedure for sludge was the same as for water sample. Detailed information on sample preparation was listed in the Supplementary materials.

Chemical analysis was performed with a Dionex Ultimate 3000 HPLC system coupled to an Applied Biosystems API 3200 triple quadrupole mass spectrometer (USA) equipped with an electrospray ionization source. An Acclaim Mixed-Mode HILIC-1 column 


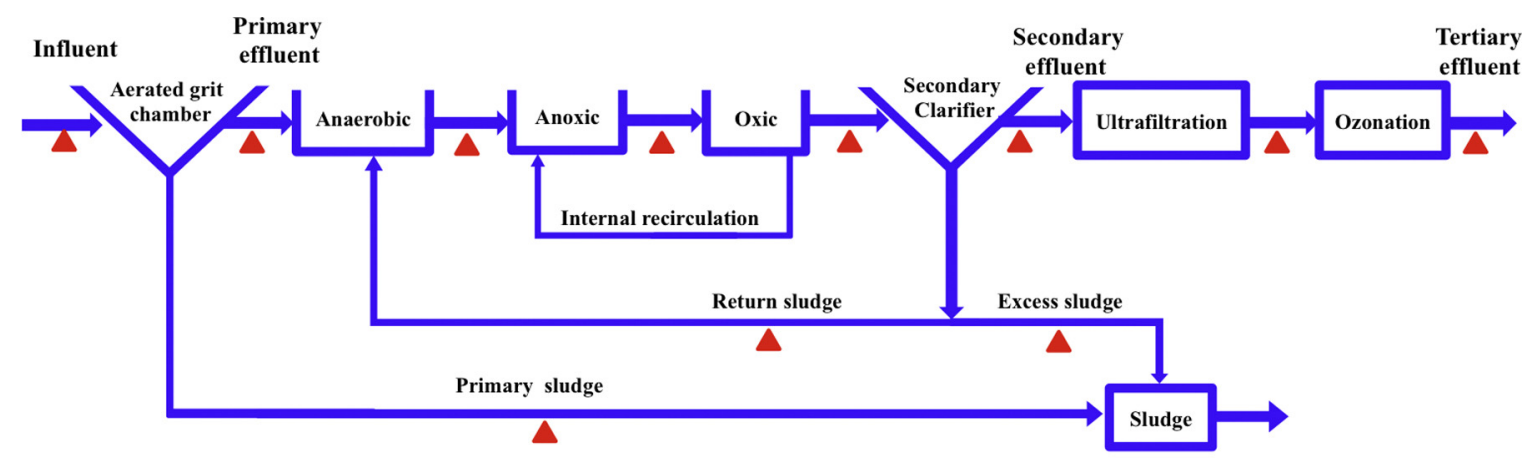

Sample sites

Fig. 1. Schematic diagram of the treatment processes in the WWTP and sampling site location.

( $3 \mu \mathrm{m}, 2 \mathrm{~mm} \times 150 \mathrm{~mm}$; Thermo, USA) was used as the analytical column at a flow rate of $0.20 \mathrm{~mL} / \mathrm{min}$. Acetonitrile was used as mobile phase $\mathrm{A}$, and $0.1 \%$ ammonium formate in water was used as mobile phase $B$. The gradient program was as follows: the mobile phase starting conditions were $40 \%$ of A for $2.0 \mathrm{~min}$, and A was increased to $55 \%$ in $3.0 \mathrm{~min}$ before being increased to $100 \%$ in $6.0 \mathrm{~min} ; 100 \%$ of $\mathrm{A}$ for $4.0 \mathrm{~min}$, followed by returning to the initial composition in $1 \mathrm{~min}$, which was maintained for $9.0 \mathrm{~min}$. The total run time was $25.0 \mathrm{~min}$. The MS system was operated in the negative electrospray ionization and multiple reactions monitoring (MRM) mode. The detail of LC-MS/MS analysis was also provided in the Supplementary materials (Table S2).

\subsection{Quality assurance and quality control}

All equipment and containers were rinsed with methanol and purified water to avoid sample contamination. For each set of samples, one procedure blank and one independent check standard were evaluated for background contamination and system performance. The internal standard method was used for quantification of each target compound. Method detection limits (MDLs) were calculated as 3 times signal-to-noise for each compound in the actual samples and ranged from 0.02 to $0.4 \mathrm{ng} / \mathrm{L}$ in wastewater, and 0.1 to $0.8 \mu \mathrm{g} / \mathrm{kg}$ in sludge samples, respectively. The calibration curve was generated across a wide range of concentrations $(0.1-200 \mu \mathrm{g} / \mathrm{L})$ and the linearity of the calibration curve in this range was confirmed $\left(r^{2}>0.99\right)$. Recoveries of target compounds in water and sludge samples were calculated to assess the accuracy of the method, and to correct the losses of analytes during analysis procedure, $\mathrm{PHBA}-\mathrm{d}_{4}$ was used as surrogate standard for PHBA, MeP- $\mathrm{d}_{4}$ for $\mathrm{MeP}, 3-\mathrm{Cl}-$ $\mathrm{MeP}$, and 3,5-2Cl-MeP, EtP- $\mathrm{d}_{5}$ for EtP, 3-Cl-EtP, and 3,5-2Cl-EtP, PrP- $\mathrm{d}_{7}$ for PrP, BuP-d $\mathrm{d}_{9}$ for BuP, PeP, HeP and OcP, BzP- $\mathrm{d}_{7}$ for BzP (Table S3). Detailed information about the calibration, recoveries, and limits of detection of the target compounds are listed in Table S3. Recoveries for parabens in the sludge samples extracted by SPE and PLE are shown in Table S4, and the recoveries of surrogate standards during analysis procedure were listed in the Supplementary materials.

\subsection{Data analysis}

All statistical analyses were performed with IBM PASW Statistics 18.0 (SPSS Inc., 1993-2007). Concentrations of target compounds below the MDLs were assigned a value equal to half of the MDLs for data analysis. The normality test of the data was analyzed using a Kolmogorov-Smirnov test. Comparison of concentrations was performed using the nonparametric Kruskal-Wallis test. It was regarded as significant difference when $p<0.05$ for the two tests.
Overall removal efficiencies of the target compounds in the conventional treatment $\left(R_{C}\right)$ and advanced treatment $\left(R_{\mathrm{A}}\right)$ were calculated as relative amounts to the influent concentrations using Eqs. (1) and (2), respectively:

$R_{C}=\left(C_{\text {Influent }}-C_{\text {Seceff }}\right) / C_{\text {Influent }} \times 100 \%$

$R_{\mathrm{A}}=\left(C_{\text {Influent }}-C_{\text {Tereff }}\right) / C_{\text {Influent }} \times 100 \%$

where $C_{\text {Influent }}, C_{\text {Seceff }}$ and $C_{\text {Tereff }}$ are the dissolved concentrations measured in influent, secondary effluent, and tertiary effluent of the WWTP, respectively.

To assess the contribution of each treatment unit to parabens removal, the relative fraction of elimination contribution (RFEC, \%) of parabens from the aqueous phase in each unit was calculated with the following equation:

RFEC $=\left(C_{\text {Inflow }}-C_{\text {Outflow }}\right) /\left(C_{\text {Influent }}-C_{\text {Tereff }}\right) \times 100 \%$

where $C_{\text {Inflow }}$ and $C_{\text {Outflow }}$ are the dissolved concentrations of compounds in inflow and outflow of each unit, respectively.

The calculations of mass flows are based on concentrations of each compound and average daily flow rates:

$W=C_{\text {dissolved }} \times Q_{\text {water }}+C_{\text {adsorbed }} \times Q_{\text {sludge }}$

where $W$ is the total mass of individual compound in aqueous and sorbed phase $(\mathrm{g} / \mathrm{d}) ; C_{\text {dissolved }}$ and $C_{\text {adsorbed }}$ represent the dissolved and adsorbed concentrations, respectively; $Q_{\text {water }}$ and $Q_{\text {sludge }}$ represent the water and sludge daily flow rates, respectively. The mass flows of total target compounds in WWTP processes are shown in Fig. S1.

The mass load of parabens that was lost due to degradation processes $\left(W_{\text {Lost }}\right)$ during activated sludge treatment was calculated using the following equation:

$W_{\text {Lost }}=W_{\text {Influent }}-W_{\text {Sludge }}-W_{\text {Effluent }}$

where $W_{\text {Influent }}$ and $W_{\text {Effluent }}$ represent the mass load of parabens in influent and secondary effluent, respectively; $W_{\text {Sludge }}$ is the mass output in primary and excess sludge.

To assess the mass variations of parabens in individual treatment stages and the whole treatment process, the fraction of mass loss $\left(R_{\text {Lost }}\right.$, \%) in each treatment unit during activated sludge treatment was calculated using the following equation:

$R_{\text {Lost }}=\left(W_{\text {inflow }}-W_{\text {outflow }}\right) / W_{\text {inflow }} \times 100 \%$

where $W_{\text {inflow }}$ and $W_{\text {outflow }}$ represent the mass loading of parabens in inflow and outflow of each unit, respectively. Generally, it is considered that losses above $20 \%$ are able to suggest clearly degradation of a chemical [25]. It should be noted that the possible 
influence of parabens degradation along the $24 \mathrm{~h}$ sampling period was not taken into account in this study.

\section{Results and discussion}

\subsection{Occurrence of target parabens, PHBA and chlorinated parabens}

The concentrations of target compounds in the wastewater (dissolved/aqueous phase, ng/L) and sludge samples (adsorbed/solid phase, $\mu \mathrm{g} / \mathrm{kg}$ d.w.) taken at each stage of the treatment are summarized in Table1 and 2, respectively. It should be noted that concentrations of $\mathrm{PeP}, \mathrm{HeP}, 3-\mathrm{Cl}-\mathrm{Mep}$ and 3-Cl-Etp were below their MDLs in all samples, which may be explained by the rare use of PeP and HeP in Beijing and the limited stability of mono-chlorinated parabens in the aquatic environment [26], respectively.

\subsubsection{Influent}

As shown in Table 1, nine target compounds were detected in influent samples. MeP and PrP were the dominant parabens in the influent, with a mean concentration of 567 and $438 \mathrm{ng} / \mathrm{L}$, respectively, which is in agreement with their ubiquitous presence in numerous cosmetic products [10]. The other two frequently used parabens, EtP $(140 \mathrm{ng} / \mathrm{L})$ and $\mathrm{BuP}(27.9 \mathrm{ng} / \mathrm{L})$, were also present in all influent samples; on the other hand, OcP $(0.08 \mathrm{ng} / \mathrm{L})$ and BzP $(0.07 \mathrm{ng} / \mathrm{L})$ were only detected at trace levels in influent. In general, the relative concentrations of the six measured parabens reflect their consumption pattern in this area. It is noteworthy that OcP with longer chain was firstly detected in water samples in the present study.

In this study, the levels of target parabens detected in the influent were comparable to those previously reported in Southern Ontario, Canada (MeP: 100-1470 ng/L; EtP: 20-270 ng/L; PrP: 200-2430 ng/L; BuP: 20-260 ng/L) [27] and Spain (MeP: 430-2920 ng/L; EtP: 52-210 ng/L; PrP: 230-810 ng/L; BuP: $20-86 \mathrm{ng} / \mathrm{L}$ ) [28]. However, the concentrations of these parabens in the influent were at least one order of magnitude less than those in Galicia, Spain (MeP: 1926-5138 ng/L; EtP: 452-549 ng/L; PrP: 1147-1302 ng/L; BuP: 150-181 ng/L) [29], and Central Pacific region of Japan (MeP: 2642 ng/L; EtP: 1036 ng/L; PrP: 1393 ng/L; BuP: $52 \mathrm{ng} / \mathrm{L}$ ) [30]. As the main metabolite and degradation product of parabens, PHBA was also found in the influent, with a mean concentration of $590 \mathrm{ng} / \mathrm{L}$, which was comparable to those previously reported in Southern Ontario, Canada (776 ng/L) [9].

Given the fact that parabens are widely used in personal care products and highly reactive with chlorine in water, relative high level of two di-chlorinated parabens, 3,5-2Cl-MeP (22.9 ng/L) and 3,5-2Cl-EtP(30.0 ng/L), were found in influent samples. Similar levels of di-chlorinated MeP were reported to occur in raw sewage water at concentrations ranging from 10 to $100 \mathrm{ng} / \mathrm{L}$ [11]. Compared to their respective parent compounds, chlorinated derivatives, especially the di-chlorinated derivatives, are more stable in the environment and more toxic to aquatic organisms [30], so these compounds are worth paying more attention to their environmental fate and toxicological properties. However, due to the lack of commercially standard for these by-products [23], limited information is available for the occurrence and behavior of chlorinated parabens in WWTPs.

\subsubsection{Secondary effluent}

After the conventional treatment with activated sludge process (anaerobic-anoxic-oxic process), only 7 target compounds, including four parabens (MeP, EtP, PrP, and BuP), two di-chlorinated parabens and PHBA, were still detectable in secondary effluents. Compared to those measured in the influents, the concentrations of target compounds reduced significantly in the secondary effluent, except PHBA, 3,5-2Cl-MeP and 3,5-2Cl-EtP were still at high levels in these samples. $\mathrm{MeP}(13.5 \mathrm{ng} / \mathrm{L})$ was also the dominant paraben in the secondary effluent, followed by $\operatorname{PrP}(1.95 \mathrm{ng} / \mathrm{L})$, EtP $(0.63 \mathrm{ng} / \mathrm{L})$, and $\mathrm{BuP}(0.05 \mathrm{ng} / \mathrm{L})$. Several studies have also reported the occurrences of parabens in secondary effluents from WWTPs with activated sludge treatments. The values in this study were slightly lower than or similar to those reported in North-western Spain (MeP: 6.1-50 ng/L; EtP: ND-9.8 ng/L; PrP: ND-21 ng/L; BuP: ND) [11], and North-eastern part of Switzerland (MeP: 4.6-423 ng/L; EtP: <0.3-17 ng/L; PrP: <0.5-28 ng/L; BuP: 0.2-3.9 ng/L) [10], but were much higher than those found in Spain, where all the parabens were below the MDLs [28].

\subsubsection{Tertiary effluent}

After the advanced treatment with ultrafiltration and ozone oxidation, 7 target compounds were still found in tertiary effluent samples. PHBA (44.9 ng/L), 3,5-2Cl-MeP (3.94 ng/L) and 3,5-2Cl-EtP $(12.2 \mathrm{ng} / \mathrm{L})$ were quantified in tertiary effluent samples at relative high level, whereas the remaining parabens, MeP (6.84 ng/L), PrP $(0.44 \mathrm{ng} / \mathrm{L}), \operatorname{EtP}(0.27 \mathrm{ng} / \mathrm{L})$, and BuP $(0.07 \mathrm{ng} / \mathrm{L})$, were at trace level. Limited information is available regarding the presence of parabens in the tertiary effluents. In the present study, the concentrations of parabens were similar to or lower than those reported in the tertiary effluents treated with chlorine in China (MeP: $5.1 \mathrm{ng} / \mathrm{L}$; EtP: $1.0 \mathrm{ng} / \mathrm{L} ; \operatorname{PrP}: 7.2 \mathrm{ng} / \mathrm{L}$; BuP: $0.3 \mathrm{ng} / \mathrm{L}$ ) [31], and with coagulation flocculation and filtration in Spain (MeP: $11 \mathrm{ng} / \mathrm{L} ; \mathrm{EtP}<1.5 \mathrm{ng} / \mathrm{L}$; $\operatorname{PrP}<0.5$ ng/L; BuP $<0.5$ ng/L) [32].

\subsubsection{Sludge}

As shown in Table 2, nine target compounds were detected in the sludge samples. The composition profiles of the detected parabens in sludge samples throughout the treatment process were similar, which may be due to large amounts of sludge were continuously cycled in the WWTPs. In addition, no significant differences were observed for the total concentrations of parabens in sludge samples $(p>0.05)$, because biodegradation played a limited role for the parabens in solid environmental matrices, indicting they were stable in sludge samples $[23,33]$.

$\mathrm{MeP}$ was the predominant paraben in the sludge, with a mean concentration of $407 \mu \mathrm{g} / \mathrm{kg}$, which was one or two orders of magnitude higher than those of $\operatorname{PrP}(27.3 \mu \mathrm{g} / \mathrm{kg})$, EtP $(4.48 \mu \mathrm{g} / \mathrm{kg})$, BuP $(3.20 \mu \mathrm{g} / \mathrm{kg})$, OcP $(1.07 \mu \mathrm{g} / \mathrm{kg})$, and BzP $(0.04 \mu \mathrm{g} / \mathrm{kg})$. The mean concentrations of PHBA, and 3,5-2Cl-MeP and 3,5-2Cl-EtP in sludge were $1071,10.8$ and $7.28 \mu \mathrm{g} / \mathrm{kg}$, respectively. The concentrations of the parabens detected in this study were similar to those found in Tarragona, Spain (MeP: 46-202 $\mu \mathrm{g} / \mathrm{kg}$; PrP: 6-10 $\mu \mathrm{g} / \mathrm{kg}$ ) [12] and Korea (MeP: 4.31-540 $\mu$ g/kg; PrP: n.d.-32.5 $\mu \mathrm{g} / \mathrm{kg}$ ) [13], while were much higher than those found in the Pearl River Delta, South China (MeP: 5.7-53.5 $\mu \mathrm{g} / \mathrm{kg}$; PrP: 3.6-17.8 $\mu \mathrm{g} / \mathrm{kg}$ ) [34] and Madrid, Spain (MeP: 5.1-26.2 $\mu \mathrm{g} / \mathrm{kg}$; PrP: 5.6-44.1 $\mu \mathrm{g} / \mathrm{kg}$ ) [33].

Recent studies have showed that parabens, as well as their chlorinated derivatives preferentially partitioned into the suspended solid phase in river water $[1,30]$, suggesting their ability to adhere to solid environmental matrices. Previous study suggested that hydrophobic interaction plays a predominant role in sorption at neutral $\mathrm{pH}$ [35]. The solubility of the compounds and the values of $K_{\mathrm{ow}}$ determining affinity to organic matter indicate that the possibility of accumulation of parabens in sludge increases proportionally to chain length of alkyl substituent. However, MeP with low $K_{\text {ow }}$ was detected at a considerable level in sludge, which may be due to its wide use in various products [32].

\subsection{Removal of targeted compounds by various processes}

To better understand the behavior of parabens in WWTPs, we calculated the elimination contribution, and the mass change 
Table 1

Summary of average concentrations of targeted compounds in water samples (ng/L).

\begin{tabular}{|c|c|c|c|c|c|c|c|c|}
\hline Analytes & $\begin{array}{l}\text { Influent } \\
\mathrm{M}(\mathrm{L}-\mathrm{H})\end{array}$ & $\begin{array}{l}\text { Aerated grit chamber } \\
\text { M (L-H) }\end{array}$ & $\begin{array}{l}\text { Anaerobic } \\
\mathrm{M}(\mathrm{L}-\mathrm{H})\end{array}$ & $\begin{array}{l}\text { Anoxic } \\
\mathrm{M}(\mathrm{L}-\mathrm{H})\end{array}$ & $\begin{array}{l}\text { Oxic } \\
\mathrm{M}(\mathrm{L}-\mathrm{H})\end{array}$ & $\begin{array}{l}\text { Secondary clarifier } \\
M(L-H)\end{array}$ & $\begin{array}{l}\text { Ultrafiltration } \\
\mathrm{M}(\mathrm{L}-\mathrm{H})\end{array}$ & $\begin{array}{l}\text { Ozonation } \\
\mathrm{M}(\mathrm{L}-\mathrm{H})\end{array}$ \\
\hline MeP & $567(211-1002)$ & $449(82.8-892)$ & $19.5(5.05-38.8)$ & $20.8(3.23-35.9)$ & $13.5(1.32-24.4)$ & $13.5(3.06-23.8)$ & $8.74(4.84-14.5)$ & $6.84(2.14-15.0)$ \\
\hline EtP & $140(32.9-220)$ & $119(26.8-204)$ & $0.86(0.50-1.11)$ & $0.77(0.58-1.02)$ & $0.36(0.20-0.48)$ & $0.63(0.38-0.80)$ & $0.70(0.36-1.06)$ & $0.27(0.08-0.70)$ \\
\hline PrP & $438(287-605)$ & $372(164-600)$ & $6.33(3.42-10.5)$ & $3.46(1.54-7.53)$ & $1.69(0.30-4.59)$ & $1.95(0.86-4.78)$ & $0.69(0.14-1.60)$ & $0.44(0.04-0.99)$ \\
\hline $\mathrm{BuP}$ & $27.9(16.6-35.5)$ & $21.4(6.70-33.4)$ & 0.20 (n.d. -0.38$)$ & 0.06 (n.d.-0.14) & 0.07 (n.d. -0.12$)$ & 0.05 (n.d. -0.07 ) & 0.08 (n.d. -0.20$)$ & $0.07(0.02-0.12)$ \\
\hline $\mathrm{PeP}$ & n.d. & n.d. & n.d. & n.d. & n.d. & n.d. & n.d. & n.d. \\
\hline $\mathrm{HeP}$ & n.d. & n.d. & n.d. & n.d. & n.d. & n.d. & n.d. & n.d. \\
\hline $\mathrm{BzP}$ & 0.07 (n.d.-0.26) & 0.06 (n.d.-0.24) & 0.03 (n.d.-0.10) & n.d. & n.d. & n.d. & n.d. & n.d. \\
\hline $\mathrm{OcP}$ & 0.08 (n.d.-0.33) & 0.06 (n.d. -0.22 ) & 0.04 (n.d.-0.15) & 0.03 (n.d.-0.10) & 0.02 (n.d.-0.09) & n.d. & n.d. & n.d. \\
\hline PHBA & $590(145-1660)$ & $491(127-1340)$ & $100(12.4-174)$ & $75.0(9.37-193)$ & $89.7(3.93-256)$ & $126(30.0-268)$ & $123(10.7-310)$ & $44.9(2.47-95.4)$ \\
\hline 3-Cl-MeP & n.d. & n.d. & n.d. & n.d. & n.d. & n.d. & n.d. & n.d. \\
\hline 3,5-2Cl-MeP & $22.9(7.55-30.0)$ & $18.5(8.01-22.8)$ & $13.5(4.30-25.0)$ & $14.5(4.04-24.6)$ & $13.3(4.81-26.3)$ & $13.6(3.74-19.1)$ & $11.7(4.34-16.9)$ & $3.94(1.05-5.62)$ \\
\hline 3-Cl-EtP & n.d. & n.d. & n.d. & n.d. & n.d. & n.d. & n.d. & n.d. \\
\hline 3,5-2Cl-EtP & $30.0(16.2-49.4)$ & $27.4(8.70-51.5)$ & $23.6(9.19-47.8)$ & $22.8(11.9-47.4)$ & $27.1(17.4-51.0)$ & $19.8(8.92-35.4)$ & $19.3(12.2-33.6)$ & $12.2(8.23-18.4)$ \\
\hline
\end{tabular}

$\mathrm{L}$ - the lowest recorded concentration; $\mathrm{H}$ - the highest recorded concentration; $\mathrm{M}$ - mean concentration; n.d.: not detected.

Table 2

Summary of average concentrations of targeted compounds in sludge samples $\left(\mu \mathrm{g} / \mathrm{kg}^{-1}, \mathrm{dw}\right)$.

\begin{tabular}{|c|c|c|c|c|c|c|c|c|}
\hline Analytes & $\begin{array}{l}\text { Influent } \\
\mathrm{M}(\mathrm{L}-\mathrm{H})\end{array}$ & $\begin{array}{l}\text { Aerated grit chamber } \\
M(L-H)\end{array}$ & $\begin{array}{l}\text { Anaerobic } \\
\mathrm{M}(\mathrm{L}-\mathrm{H})\end{array}$ & $\begin{array}{l}\text { Anoxic } \\
M(L-H)\end{array}$ & $\begin{array}{l}\text { Oxic } \\
M(L-H)\end{array}$ & $\begin{array}{l}\text { Return sludge } \\
\mathrm{M}(\mathrm{L}-\mathrm{H})\end{array}$ & $\begin{array}{l}\text { Excess sludge } \\
\mathrm{M}(\mathrm{L}-\mathrm{H})\end{array}$ & $\begin{array}{l}\text { Internal sludge } \\
\mathrm{M}(\mathrm{L}-\mathrm{H})\end{array}$ \\
\hline MeP & $448(393-507)$ & $409(304-494)$ & $354(290-388)$ & $444(360-556)$ & $379(273-553)$ & $423(291-498)$ & $413(350-5$ & $391(27$ \\
\hline EtP & $5.43(4.72-5.87)$ & $3.75(2.38-5.28)$ & $3.87(2.35-5.56)$ & $3.81(1.89-5.44)$ & $4.80(3.44-7.05)$ & $4.32(2.78-6.80)$ & $5.27(3.47-6.22)$ & $4.58(1.14-6.33)$ \\
\hline PrP & $46.2(20.2-82.4)$ & $45.5(31.2-80.3)$ & $19.8(13.0-24.4)$ & $22.6(15.5-27.8)$ & $23.7(17.4-29.3)$ & $20.8(14.5-28.2)$ & $21.0(13.0-29.9)$ & $18.9(15.8-23.6)$ \\
\hline BuP & $5.71(1.15-10.3)$ & $5.36(1.09-10.4)$ & $3.50(1.00-8.97)$ & $2.20(1.91-2.85)$ & $2.10(0.77-3.54)$ & $2.05(0.62-2.82)$ & $2.03(0.54-2.65)$ & $2.65(1.13-4.57)$ \\
\hline PeP & n.d. & n.d. & n.d. & n.d. & n.d. & n.d. & n.d. & n.d. \\
\hline $\mathrm{HeP}$ & n.d. & n.d. & n.d. & n.d. & n.d. & n.d. & n.d. & n.d. \\
\hline $\mathrm{BzP}$ & n.d. & n.d. & n.d. & n.d. & n.d. & n.d. & 0.32 (n.d.-0.74) & n.d. \\
\hline OcP & $1.84(0.60-2.68)$ & $1.90(1.17-2.43)$ & $0.65(0.28-0.90)$ & $0.99(0.64-1.38)$ & $0.61(0.47-0.68)$ & $0.73(0.34-1.07)$ & $0.97(0.45-1.57)$ & $0.85(0.51-1.78)$ \\
\hline PHBA & $1143(488-1709)$ & $937(292-1621)$ & $1279(340-1885)$ & $1008(795-1535)$ & 993 (492-1395) & $1120(530-1940)$ & $1059(610-1650)$ & $1031(438-1645)$ \\
\hline 3-Cl-MeP & n.d. & n.d. & n.d. & n.d. & n.d. & n.d. & n.d. & n.d. \\
\hline 3,5-2Cl-MeP & $6.85(4.07-11.2)$ & $7.63(6.46-10.2)$ & $11.2(3.55-15.2)$ & $9.36(8.20-10.6)$ & $13.4(12.9-14.3)$ & $10.3(5.09-18.0)$ & $10.1(5.01-13.3)$ & $9.77(5.88-15.3)$ \\
\hline 3-Cl-EtP & n.d. & n.d. & n.d. & n.d. & n.d. & n.d. & n.d. & n.d. \\
\hline 3,5-2Cl-EtP & $7.61(5.29-10.5)$ & $7.63(2.82-13.6)$ & $7.39(3.38-13.1)$ & $6.55(3.49-10.7)$ & $7.18(2.76-11.3)$ & $6.75(1.30-9.95)$ & $6.44(3.60-10.5)$ & $8.68(2.83-11.7)$ \\
\hline
\end{tabular}

$\mathrm{L}$ - the lowest recorded concentration; $\mathrm{H}$ - the highest recorded concentration; $\mathrm{M}$ - mean concentration; n.d.: not detected.

Table 3

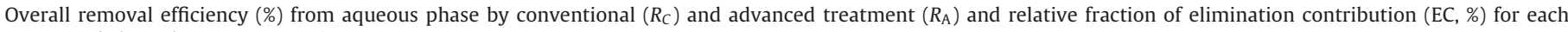
compound along the treatment units.

\begin{tabular}{|c|c|c|c|c|c|c|c|c|c|}
\hline \multirow[t]{2}{*}{ Analytes } & \multicolumn{6}{|l|}{ Conventional treatment } & \multicolumn{3}{|c|}{ Advanced treatment } \\
\hline & Aerated grit chamber & Anaerobic & Anoxic & Aerobic & Secondary clarifier & $R_{C}$ & Ultrafiltration & Ozonation & $R_{\mathrm{A}}$ \\
\hline $\mathrm{MeP}$ & 21.0 & 76.7 & -0.23 & 1.3 & 0.01 & 97.6 & 0.85 & 0.34 & 98.8 \\
\hline EtP & 14.9 & 84.6 & 0.07 & 0.29 & -0.19 & 99.6 & -0.05 & 0.31 & 99.8 \\
\hline PrP & 15.9 & 83.7 & 0.66 & 0.40 & -0.06 & 99.6 & 0.29 & 0.06 & 99.9 \\
\hline $\mathrm{BuP}$ & 23.3 & 76.3 & 0.51 & -0.04 & 0.05 & 99.8 & -0.09 & 0.03 & 99.7 \\
\hline PeP & - & - & - & - & - & - & - & - & - \\
\hline $\mathrm{HeP}$ & - & - & - & - & - & - & - & - & - \\
\hline $\mathrm{BzP}$ & 7.7 & 53.9 & 38.4 & - & - & $>92.3$ & - & - & $>92.3$ \\
\hline $\mathrm{OcP}$ & 33.3 & 21.2 & 15.2 & 3.0 & - & $>60.6$ & - & - & $>60.6$ \\
\hline PHBA & 18.2 & 71.7 & 4.6 & -2.7 & -6.7 & 78.6 & 0.53 & 14.4 & 92.4 \\
\hline 3-Cl-MeP & - & - & - & - & - & - & - & - & - \\
\hline 3,5-2Cl-MeP & 23.0 & 26.3 & -4.9 & 6.0 & -1.2 & 40.7 & 9.9 & 40.9 & 82.8 \\
\hline 3-Cl-EtP & - & - & - & - & - & - & - & - & - \\
\hline 3,5-2Cl-EtP & 14.8 & 21.2 & 4.6 & 3.8 & 12.9 & 33.9 & 3.1 & 39.6 & 59.2 \\
\hline
\end{tabular}

percentages of the selected parabens in each step. In addition, the overall removal efficiencies of conventional treatment and advanced treatment are also presented in Table 3.

\subsubsection{Conventional treatment processes}

3.2.1.1. Parabens and PHBA. The fate of parabens and PHBA in each stage of this WWTP was investigated by their distributions between wastewater and sludge. Generally, due to their low volatility, volatilization is not expected to be an important fate process for parabens and PHBA [23]. Thus, biodegradation and adsorption are two main processes responsible for the fates of parabens and PHBA in WWTPs [36].
In the primary treatment system, low and similar percentages of primary removal (7.7-23.2\%) were found for most parabens and PHBA except for OcP (33.3\%). Generally, primary sedimentation combined with short aeration time $(0.5 \mathrm{~h})$ is not expected to remove masses of pollutants, and the limited removal depends mostly on sorption potential to suspend solids deposited from primary sedimentation. It should be noted that OcP was moderately eliminated (33.3\%) during primary treatment in the present study, which was in agreement with its high hydrophobicity $\left(\log K_{\text {ow }}=4.88\right)$.

In the activated sludge system, the overall removal efficiencies of parabens from aqueous phase were over 97.6\% (Table 3 ). The mass balance results for each analyte were expressed in mass fractions (\%) detected in secondary effluent, primary and excess 


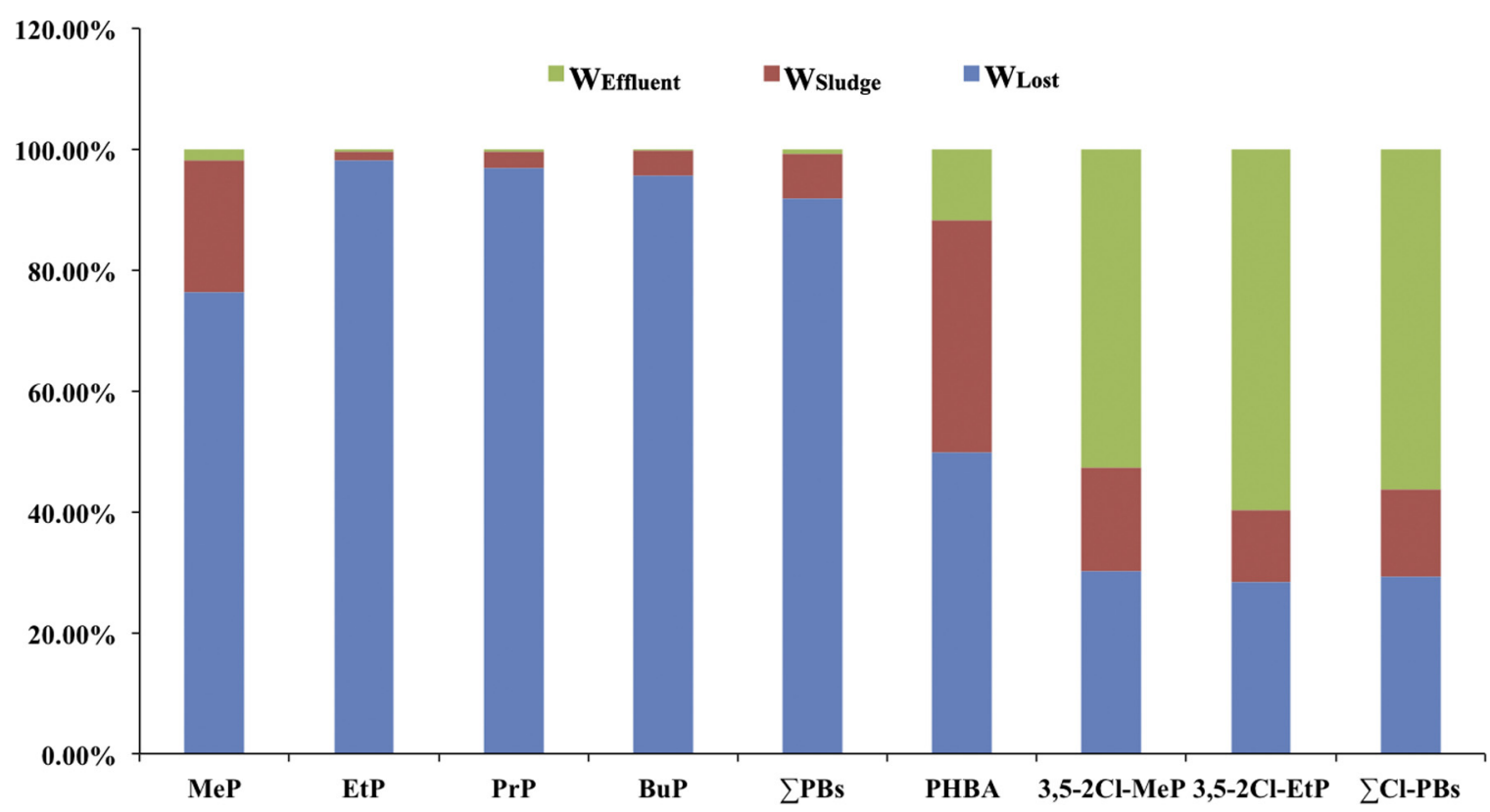

Fig.2 - Mass fractions (\%) of target compounds detected in secondary effluent (WEffluent), primary and excess sludge (Wsludge), and lost (WLost) during activated sludge treatment.

Fig. 2. Mass fractions (\%) of target compounds in secondary effluent ( $\left.W_{\text {Effluent }}\right)$, primary and excess sludge $\left(W_{\text {Sludge }}\right)$, and lost $\left(W_{\text {Lost }}\right)$ during activated sludge treatment.

sludge (adsorption), and lost (biodegraded or transformed) relative to initial mass load in influent (Fig. 2). In the present study, the fractions of mass losses of total parabens ( $\sum \mathrm{PBs}$ ) due to degradation accounted for $91.8 \%$ of initial loadings, while the contribution of sorption and output of primary and excess sludge was much less (7.5\%), indicating that biodegradation played a significant role in the removal of parabens during the treatment process.

As illustrated in Fig. 3, the mass change percentages of total parabens ( $\sum$ PBs) were $26 \%, 6 \%,-6 \%$, and $-5 \%$ in anaerobic tank, anoxic tank, oxic tank and secondary clarifier, respectively. The high mass change in the anaerobic tank suggested that parabens were mainly biodegraded in this unit, which is in accordance with previous report that levels of the parabens decreased significantly during anaerobic processes, the first treatment unit in a sewage treatment plant [31]. However, several studies have reported that these compounds are readily biodegradable under aerobic conditions, while only partially degraded under anaerobic conditions [37,38]. This may be due to their relative low levels in the primary effluent, which can be rapidly degraded when they enter into the anaerobic tank. On the contrary, negative mass loss was observed in the oxic tank, which was possibly due to desorption of the parabens from sludge in this unit.

The concentrations of parabens sequentially decreased in anaerobic tank, anoxic tank, oxic tank and secondary clarifier (Table 1). On the other hand, the concentration of PHBA, a very common contaminant in a great variety of wastewaters, did not change correspondingly in this progress or even increased slightly in oxic tank and secondary clarifier. Previous study has shown PHBA was refractory to anaerobic biological treatment [39], leading to little change of PHBA in anaerobic tank and anoxic tank. Additionally, it is reported that the first step of parabens degradation was the hydrolysis of the ester bond to produce PHBA under aerobic condition [40]. Therefore, this result suggests that some PHBA, the main microbial degradation metabolite of parabens, was formed by degradation of parabens during the activated sludge treatment, which resulted in the increase of PHBA levels in oxic tank and secondary clarifier.
The overall removal efficiency of individual target compound by the conventional treatment is shown in Table 3. Most commonly used parabens, MeP, PrP, EtP, and BuP, were efficiently removed (97.6-99.8\%) during this progress, while PHBA showed moderate removal efficiency of $78.6 \%$. Similar results were also found in other WWTPs from the United Kingdom [41], Spain [11], and Denmark [42], with a very high removal efficiency exceeding $90 \%$. It is reported that the persistence of parabens seems to slightly increase with the length of the alkyl chain [11]. However, the two parabens with longer alkyl chains, BzP and OcP, which were not detected in effluent (the calculation of removal is limited by the MDLs), were removed more effectively during the conventional treatment in this study, which is consistent with reports that parabens with longer alkyl chains underwent faster degradation than those with short alkyl chains in wastewater [23].

3.2.1.2. Chlorinated parabens. Despite the concentrations of two di-chlorinated parabens decreased as water treatment progressed, 3,5-2Cl-MeP and 3,5-2Cl-EtP were poorly removed by conventional treatment, with a removal efficiency of $40.7 \%$ and $33.9 \%$, respectively. The fractions of mass losses resulting from degradation and sorption for two chlorinated parabens accounted for $29.3 \%$ and $14.4 \%$ of initial loadings, respectively (Fig. 2), suggesting that chlorinated parabens are relatively stable in wastewater during this process. In the activated sludge system, the mass change percentages of total chlorinated parabens ( $\sum$ Cl-PBs) were observed at $-11 \%, 22 \%,-28 \%$ and $14 \%$ in anaerobic, anoxic, aerobic units, and secondary clarifier, respectively (Fig. 3). The low mass change percentages in the four activated sludge treatment units also suggested that biodegradation accounted for minor contribution to the removal of chlorinated parabens. This may be due to the fact that chlorinated derivatives were resistant to biodegrading and survived initial stages of treatment carried out in WWTPs. In addition, the relatively low $\log K_{\text {ow }}$ values for 3,5-2Cl-MeP (2.88) and 3,52Cl-EtP (3.32) also indicated that sorption to sludge had a limited contribution to the removal of di-chlorinated parabens. Overall, 


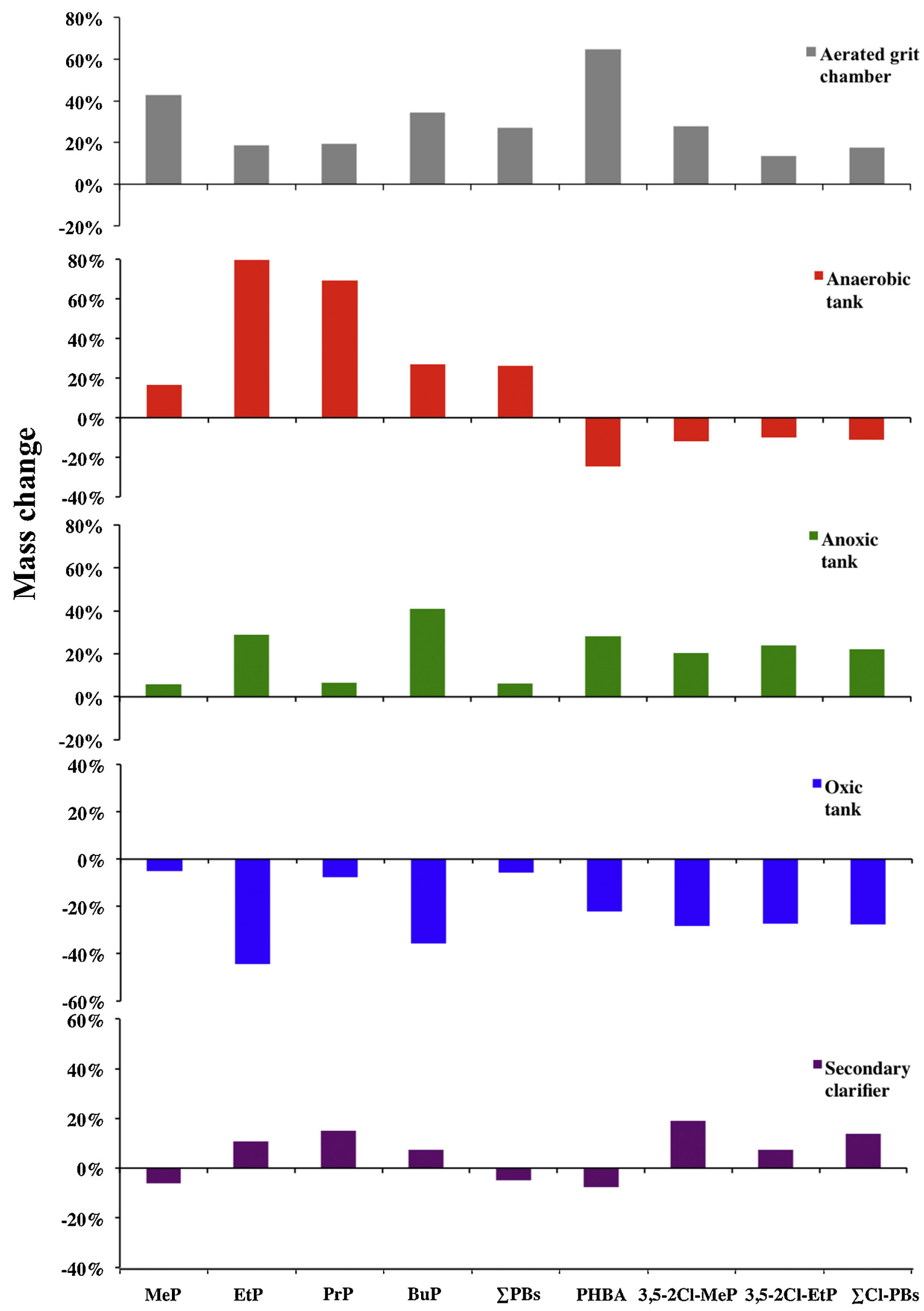

Fig. 3. The fraction of mass change $\left(R_{\text {loss }}\right)$ in each unit during activated sludge treatment. 
Table 4

Hazard quotients (HQs) for the aquatic organisms as calculated from measured environmental concentrations (MECs) and predicted no effect concentrations (PNECs).

\begin{tabular}{|c|c|c|c|c|c|c|}
\hline \multirow[t]{2}{*}{ Analytes } & \multirow[t]{2}{*}{ Taxonomic group } & \multirow{2}{*}{$\begin{array}{l}\text { PNEC } \\
(\mathrm{ng} / \mathrm{L})\end{array}$} & \multicolumn{2}{|c|}{ MEC (ng/L) } & \multicolumn{2}{|l|}{ HQ } \\
\hline & & & SEC & TER & SEC & TER \\
\hline \multirow[t]{4}{*}{$\mathrm{MeP}$} & Algae & 80,000 & 23.8 & 15.0 & $3.0 \times 10^{-4}$ & $1.9 \times 10^{-4}$ \\
\hline & Bacteria & 2,500 & & & $9.5 \times 10^{-3}$ & $6.0 \times 10^{-3}$ \\
\hline & Invertebrate & 18,700 & & & $1.3 \times 10^{-3}$ & $8.0 \times 10^{-4}$ \\
\hline & Fish & 1,600 & & & $1.5 \times 10^{-2}$ & $9.4 \times 10^{-3}$ \\
\hline \multirow[t]{4}{*}{ EtP } & Algae & 52,000 & 0.80 & 0.70 & $1.5 \times 10^{-5}$ & $1.3 \times 10^{-5}$ \\
\hline & Bacteria & 4,600 & & & $1.7 \times 10^{-4}$ & $1.5 \times 10^{-4}$ \\
\hline & Invertebrate & 7,400 & & & $1.1 \times 10^{-4}$ & $9.5 \times 10^{-5}$ \\
\hline & Fish & 800 & & & $1.0 \times 10^{-3}$ & $8.8 \times 10^{-4}$ \\
\hline \multirow[t]{4}{*}{ PrP } & Algae & 36,000 & 4.78 & 0.99 & $1.3 \times 10^{-4}$ & $2.8 \times 10^{-5}$ \\
\hline & Bacteria & 260 & & & $1.8 \times 10^{-2}$ & $3.8 \times 10^{-3}$ \\
\hline & Invertebrate & 2,000 & & & $2.4 \times 10^{-3}$ & $5.0 \times 10^{-4}$ \\
\hline & Fish & 400 & & & $1.2 \times 10^{-2}$ & $2.5 \times 10^{-3}$ \\
\hline \multirow[t]{4}{*}{ BuP } & Algae & 8,000 & 0.07 & 0.12 & $8.8 \times 10^{-6}$ & $1.5 \times 10^{-5}$ \\
\hline & Bacteria & 1,200 & & & $5.8 \times 10^{-5}$ & $1.0 \times 10^{-4}$ \\
\hline & Invertebrate & 470 & & & $1.5 \times 10^{-4}$ & $2.6 \times 10^{-4}$ \\
\hline & Fish & 300 & & & $2.3 \times 10^{-4}$ & $4.0 \times 10^{-4}$ \\
\hline \multirow[t]{4}{*}{$\mathrm{BzP}$} & Algae & 1,200 & n.d. & n.d. & - & - \\
\hline & Bacteria & 110 & & & - & - \\
\hline & Invertebrate & 1,000 & & & - & - \\
\hline & Fish & 200 & & & - & - \\
\hline \multirow[t]{2}{*}{ 3,5-2Cl-MeP } & Bacteria & 3,000 & 19.1 & 5.62 & $6.4 \times 10^{-3}$ & $1.9 \times 10^{-3}$ \\
\hline & Invertebrate & 16,000 & & & $1.2 \times 10^{-3}$ & $3.5 \times 10^{-4}$ \\
\hline \multirow[t]{2}{*}{ 3,5-2Cl-EtP } & Bacteria & 3,600 & 35.4 & 18.4 & $9.8 \times 10^{-3}$ & $5.1 \times 10^{-3}$ \\
\hline & Invertebrate & 13,000 & & & $2.7 \times 10^{-3}$ & $1.4 \times 10^{-3}$ \\
\hline
\end{tabular}

MEC: max measured concentrations in secondary effluent and tertiary effluent; SEC: secondary effluent; TER: tertiary effluent

the results showed that both biodegradation and adsorption might play an insignificant role in the removal of chlorinated parabens by conventional treatment.

\subsubsection{Advanced treatment processes}

Despite their relative high removal rates, a fair amount of parabens in the secondary effluent was still released into the aquatic environment. For the treatment of these compounds, the advanced treatment processes, ultrafiltration and ozonation, may need to be introduced.

3.2.2.1. Ultrafiltration. Compared to the concentrations of parabens in secondary effluent, similar or higher levels of these compounds were observed in the effluent of ultrafiltration process. This result may be explained by that parabens is difficult to be retained by size exclusions, since the UF membrane pores are larger than the molecules of target compounds [43]. Additionally, some parabens may be released from membrane during backwashing or at high $\mathrm{pH}$ variation [44]. Therefore, as shown in Table 3, the UF membranes had little elimination contributions $(<1 \%)$ to the target compounds except for 3,5-2Cl-MeP (9.9\%) and 3,5-2Cl-EtP (3.1\%). Considering the molecular sizes of di-chlorinated derivatives are expected to be larger than those of parent parabens, their relative high removal efficiencies in this process were reasonable.

3.2.2.2. Ozonation. Due to its higher oxidation potential and less by-products, ozone was the most commonly used oxidizing agents for the removal of organic compounds in wastewater treatment [45]. Table 3 shows the overall removal efficiencies of selected compounds by ozonation treatment. Excellent removal efficiencies (98.8-100\%) were observed in the process of ozonation, which is in agreement with previous result that an amount of ozone could result in the removal of $99 \%$ of parabens in a short time [46]. The reaction kinetics and degradation mechanism of parabens during ozonation were investigated in several studies, and it has been shown that both hydroxyl radicals and hydrated electrons could rapidly react with parabens during this process [47-49]. Because of their high removal efficiencies in the conventional treatment, only a small fraction of parabens was further reduced by the ozonation. It should be noted that the removal efficiencies of parent parabens, MeP, EtP, PrP and BuP, were higher than those of PHBA and two di-chlorinated parabens (Table 3). As one of two major breakdown products generated during ozonation of parabens, PHBA was partially removed in this process (92.4\%). This may be explained by the fact that the by-products generated during the ozonation are more resistant to further ozonation than the parent compounds [46]. The di-chlorinated parabens, 3,5-2Cl-MeP (82.8\%) and 3,5$2 \mathrm{Cl}$-EtP (59.2\%), also showed limited removals in this process. This may be due to their strong sorption onto sludge particles, which decreased the efficiency of the process for $\mathrm{O}_{3}$ oxidation. Additionally, the di-chlorinated parabens were rather resistant to undergo further ozone oxidation or cleavage of the aromatic ring. Therefore, if they are generated in a real life situation, their presence in the aquatic environment appears to be feasible [26].

\subsection{Environmental risk assessment}

In the present study, several parabens and their metabolite, PHBA, together with two di-chlorinated parabens, were frequently detected in secondary and tertiary effluent. Recent reports have demonstrated that their presence in aquatic environment may pose potential hazard to the aquatic organisms [14,15]. Thus, it is necessary to assess the ecological risk of these compounds with the measured environmental concentrations (MECs) on organisms. Hazard quotients (HQs, ratios of the MECs of selected parabens and the predicted no effect concentrations (PNECs)) were usually calculated for risk assessment. Generally, a PNEC value was derived from the lowest effect concentration by applying assessment factors of 1000 and 100 for acute and chronic toxicity, respectively. If the HQ value is less than 1 , then risk to the environment is considered low [15].

According to limited data concerning the acute and chronic toxicity of parabens, the acute median effective concentrations $\left(\mathrm{EC}_{50} \mathrm{~s}\right)$ and no observed effect concentrations (NOECs) of the selected parabens to various aquatic organisms are summarized in Tables S5 and S6, respectively. On the basis of these data, HQs 
were calculated with the most sensitive values of $\mathrm{EC}_{50}$ and NOEC, and presented in Table 4. After the conventional treatment, low HQ values of parabens $\left(1.8 \times 10^{-2}-8.8 \times 10^{-6}\right)$ were found in the secondary effluent, suggesting little potential adverse ecological consequences on aquatic organisms. Although HQ values of all the parabens $\left(1.4 \times 10^{-3}-9.5 \times 10^{-5}\right)$ continued to decrease in tertiary effluent, the risks of parabens did not significantly decrease after advanced treatment. All the ratios are much lower than 1, indicting that parabens and their chlorinated derivatives are not likely to produce biological effects at environmentally relevant levels in aquatic ecosystems. Taking into consideration the fact that several degradation products with higher toxicity than their parent parabens would form in the advanced oxidation $[47,48]$, the risks of parabens, especially the degradation products, on organisms required further investigations.

\section{Conclusions}

In the present study, nine target compounds, including six parabens, two di-chlorinated parabens and PHBA, were detected in water and sludge samples. For the target compounds, parabens could be readily degraded and eliminated efficiently in the conventional treatment, while PHBA and di-chlorinated parabens are more stable during this process. After the advanced treatment processes, PHBA could be effectively removed at high rates, while chlorinated parabens were only partially removed. Mass flow results showed that advanced treatment processes are effective to reduce the release of parabens into aquatic environment. Risk assessment showed the risks of parabens and their chlorinated derivatives are negligible at environmentally relevant concentrations.

\section{Acknowledgements}

This work was supported by the National Basic Research Program of China (2014CB114402), the National Natural Science Foundation of China (No. 21407008, 21477143, 21321004 and 21277011), the Strategic Priority Research Program of the Chinese Academy of Sciences (XDB14010201), the Fundamental Research Funds for the Central Universities (FRF-BR-13-005), China Postdoctoral Science Foundation (2014M550619), and State Key Laboratory of Environmental Chemistry and Ecotoxicology, Research Center for Eco-Environmental Sciences, Chinese Academy of Sciences (KF2013-07).

\section{Appendix A. Supplementary data}

Supplementary data associated with this article can be found, in the online version, at http://dx.doi.org/10.1016/j.jhazmat.2015.06. 060

\section{References}

[1] D. Bledzka, J. Gromadzinska, W. Wasowicz, Parabens. From environmental studies to human health, Environ. Int. 67 (2014) 27-42.

[2] Y. Guo, K. Kannan, A survey of phthalates and parabens in personal care products from the United States and its implications for human exposure, Environ. Sci. Technol. 47 (2013) 14442-14449.

[3] Y. Guo, L. Wang, K. Kannan, Phthalates and parabens in personal care products from china: concentrations and human exposure, Arch. Environ. Contam. Toxicol. 66 (2014) 113-119.

[4] M. Gorga, M. Petrovic, D. Barcelo, Multi-residue analytical method for the determination of endocrine disruptors and related compounds in river and waste water using dual column liquid chromatography switching system coupled to mass spectrometry, J. Chromatogr. A 1295 (2013) 57-66.

[5] N. Jonkers, A. Sousa, S. Galante-Oliveira, C.M. Barroso, H.-P.E. Kohler, W. Giger, Occurrence and sources of selected phenolic endocrine disruptors in Ria de Aveiro, Portugal, Environ. Sci. Pollut. Res. 17 (2010) 834-843.

[6] L. Renz, C. Volz, D. Michanowicz, K. Ferrar, C. Christian, D. Lenzner, T. El-Hefnawy, A study of parabens and bisphenol A in surface water and fish brain tissue from the Greater Pittsburgh Area, Ecotoxicology 22 (2013) 632-641

[7] R.A. Perez, B. Albero, E. Miguel, C. Sanchez-Brunete, Determination of parabens and endocrine-disrupting alkylphenols in soil by gas chromatography-mass spectrometry following matrix solid-phase dispersion or in-column microwave-assisted extraction: a comparative study, Anal. Bioanal. Chem. 402 (2012) 2347-2357.

[8] L. Wang, C.Y. Liao, F. Liu, Q. Wu, Y. Guo, H.B. Moon, H. Nakata, K. Kannan, Occurrence and human exposure of $p$-hydroxybenzoic acid esters (parabens), bisphenol A diglycidyl ether (BADGE), and their hydrolysis products in indoor dust from the United States and three East Asian Countries, Environ. Sci. Technol. 46 (2012) 11584-11593.

[9] E. Blanco, M.D. Casais, M.D. Mejuto, R. Cela, Combination of off-line solid-phase extraction and on-column sample stacking for sensitive determination of parabens and $p$-hydroxybenzoic acid in waters by non-aqueous capillary electrophoresis, Anal. Chim. Acta 647 (2009) $104-111$.

[10] N. Jonkers, H.P.E. Kohler, A. Dammshauser, W. Giger, Mass flows of endocrine disruptors in the Glatt River during varying weather conditions, Environ. Pollut. 157 (2009) 714-723

[11] I. Gonzalez-Marino, J.B. Quintana, I. Rodriguez, R. Cela, Evaluation of the occurrence and biodegradation of parabens and halogenated by-products in wastewater by accurate-mass liquid chromatography-quadrupole-time-of-flight-mass spectrometry (LC-OTOF-MS), Water Res. 45 (2011) 6770-6780.

[12] A. Nieto, F. Borrull, R.M. Marce, E. Pocurull, Determination of personal care products in sewage sludge by pressurized liquid extraction and ultra high performance liquid chromatography-tandem mass spectrometry, J. Chromatogr. A 1216 (2009) 5619-5625.

[13] C. Liao, S. Lee, H.B. Moon, N. Yamashita, K. Kannan, Parabens in sediment and sewage sludge from the United States, Japan, and Korea: spatial distribution and temporal trends, Environ. Sci. Technol. 47 (2013) 10895-10902.

[14] M. Inui, T. Adachi, S. Takenaka, H. Inui, M. Nakazawa, M. Ueda, H. Watanabe, C. Mori, T. Iguchi, K. Miyatake, Effect of UV screens and preservatives on vitellogenin and choriogenin production in male medaka (Oryzias latipes), Toxicology 194 (2003) 43-50

[15] M. Terasaki, R. Abe, M. Makino, N. Tatarazako, Chronic toxicity of paraben and their chlorinated by-products in Ceriodaphnia dubia, Environ. Toxicol. (2013), http://dx.doi.org/10.1002/tox.21944

[16] F.A. Andersen, Final amended report on the safety assessment of methylparaben, ethylparaben, propylparaben, isopropylparaben, butylparaben, isobutylparaben, and benzylparaben as used in cosmetic products, Int. J. Toxicol. 27 (2008) 1-82.

[17] L. Nunez, J.L. Tadeo, A.I. Garcia-Valcarcel, E. Turiel, Determination of parabens in environmental solid samples by ultrasonic-assisted extraction and liquid chromatography with triple quadrupole mass spectrometry, J. Chromatogr. A 1214 (2008) 178-182.

[18] R. Golden, J. Gandy, G. Vollmer, A review of the endocrine activity of parabens and implications for potential risks to human health, Crit. Rev. Toxicol. 35 (2005) 435-458

[19] M. Gonzalez-Doncel, J.E. Garcia-Maurino, L. San Segundo, E.M. Beltran, S Sastre, C. Fernandez Torija, Embryonic exposure of medaka (Oryzias latipes) to propylparaben: effects on early development and post-hatching growth, Environ. Pollut. 184 (2014) 360-369.

[20] J. Boberg, C. Taxvig, S. Christiansen, U. Hass, Possible endocrine disrupting effects of parabens and their metabolites, Reprod. Toxicol. 30 (2010) 301-312.

[21] P. Westerhoff, Y. Yoon, S. Snyder, E. Wert, Fate of endocrine-disruptor, pharmaceutical, and personal care product chemicals during simulated drinking water treatment processes, Environ. Sci. Technol. 39 (2005) 6649-6663.

[22] M. Terasaki, M. Makino, N. Tatarazako, Acute toxicity of parabens and their chlorinated by-products with Daphnia magna and Vibrio fischeri bioassays, J. Appl. Toxicol. 29 (2009) 242-247.

[23] C. Haman, X. Dauchy, C. Rosin, J.-F. Munoz, Occurrence, fate and behavior of parabens in aquatic environments: a review, Water Res. 68 (2015) 1-11.

[24] I. Gonzalez-Marino, J.B. Quintana, I. Rodriguez, R. Cela, Simultaneous determination of parabens, triclosan and triclocarban in water by liquid chromatography/electrospray ionisation tandem mass spectrometry, Rapid Commun. Mass. Spectrom. 23 (2009) 1756-1766

[25] A. Katsoyiannis, C. Samara, Persistent organic pollutants (POPs) in the conventional activated sludge treatment process: fate and mass balance, Environ. Res. 97 (2005) 245-257.

[26] P. Canosa, I. Rodriguez, E. Rubi, N. Negreira, R. Cela, Formation of halogenated by-products of parabens in chlorinated water, Anal. Chim. Acta 575 (2006) $106-113$.

[27] H.B. Lee, T.E. Peart, M.L. Svoboda, Determination of endocrine-disrupting phenols, acidic pharmaceuticals, and personal-care products in sewage by solid-phase extraction and gas chromatography-mass spectrometry, J. Chromatogr. A 1094 (2005) 122-129.

[28] P. Canosa, I. Rodriguez, E. Rubi, M.H. Bollain, R. Cela, Optimisation of a solid-phase microextraction method for the determination of parabens in water samples at the low ng per litre level, J. Chromatogr. A 1124 (2006) 3-10.

[29] I. Gonzalez-Marino, J. Benito Quintana, I. Rodriguez, R. Cela, Simultaneous determination of parabens, triclosan and triclocarban in water by liquid chromatography/electrospray ionisation tandem mass spectrometry, Rapid Commun. Mass. Spectrom. 23 (2009) 1756-1766. 
[30] M. Terasaki, Y. Takemura, M. Makino, Paraben-chlorinated derivatives in river waters, Environ. Chem. Lett. 10 (2012) 401-406.

[31] Y. Yu, Q. Huang, Z. Wang, K. Zhang, C. Tang, J. Cui, J. Feng, X. Peng, Occurrence and behavior of pharmaceuticals, steroid hormones, and endocrine-disrupting personal care products in wastewater and the recipient river water of the Pearl River Delta, South Delta, J. Environ. Monit. 13 (2011) 871-878.

[32] E. Carmona, V. Andreu, Y. Pico, Occurrence of acidic pharmaceuticals and personal care products in Turia River Basin: from waste to drinking water, Sci. Total. Environ. 484 (2014) 53-63.

[33] B. Albero, R. Ana Perez, C. Sanchez-Brunete, J. Luis Tadeo, Occurrence and analysis of parabens in municipal sewage sludge from wastewater treatment plants in Madrid (Spain), J. Hazard. Mater. 239 (2012) 48-55.

[34] Y.Y. Yu, Q.X. Huang, J.L. Cui, K. Zhang, C.M. Tang, X.Z. Peng, Determination of pharmaceuticals, steroid hormones, and endocrine-disrupting personal care products in sewage sludge by ultra-high-performance liquid chromatography-tandem mass spectrometry, Anal. Bioanal. Chem. 399 (2011) 891-902.

[35] H. Yamamoto, M. Watanabe, S. Katsuki, Y. Nakamura, S. Moriguchi, Y. Nakamura, J. Sekizawa, Preliminary ecological fisk assessment of butylparaben and benzylparaben -2 . Fate and partitioning in aquatic environments, Environ. Sci. 14 (2007) 97-105.

[36] J.L. Liu, M.H. Wong, Pharmaceuticals and personal care products (PPCPs): a review on environmental contamination in China, Environ. Int. 59 (2013) $208-224$.

[37] T. Madsen, H.B. Boyd, D. Nylén, A.R. Pedersen, G.I. Petersen, F. Simonsen, Environmental and Health Assessment of Substances in Household Detergents and Cosmetic Detergent Products, Danish Environmenal Protection Agency, 2001.

[38] L.H. Leal, N. Vieno, H. Temmink, G. Zeeman, C.J. Buisman, Occurrence of xenobiotics in gray water and removal in three biological treatment systems, Environ. Sci. Technol. 44 (2010) 6835-6842.

[39] S. Tabassum, O. Sulaiman, M. Ibrahim, R. Hashim, T. Altamash, Removal of chemically hazardous $p$-hydroxybenzoic acid during total chlorine free bleaching process of Hevea brasiliensis, J. Cleaner Prod. 25 (2012) 68-72.
[40] N. Valkova, F. Lepine, L. Valeanu, M. Dupont, L. Labrie, J.G. Bisaillon, R. Beaudet, F. Shareck, R. Villemur, Hydrolysis of 4-hydroxybenzoic acid esters (parabens) and their aerobic transformation into phenol by the resistant Enterobacter cloacae strain EM, Appl. Environ. Microbiol. 67 (2001) 2404-2409.

[41] B. Kasprzyk-Hordern, R.M. Dinsdale, A.J. Guwy, The removal of pharmaceuticals personal care products, endocrine disruptors and illicit drugs during wastewater treatment and its impact on the quality of receiving waters, Water Res. 43 (2009) 363-380.

[42] H.R. Andersen, M. Lundsbye, H.V. Wedel, E. Eriksson, A. Ledin, Estrogenic personal care products in a greywater reuse system, Water Sci. Technol. 56 (2007) 45-49.

[43] E. Sahar, R. Messalem, H. Cikurel, A. Aharoni, A. Brenner, M. Godehardt, M. Jekel, M. Ernst, Fate of antibiotics in activated sludge followed by ultrafiltration (CAS-UF) and in a membrane bioreactor (MBR), Water Res. 45 (2011) 4827-4836.

[44] F.A. Caliman, M. Gavrilescu, Pharmaceuticals, personal care products and endocrine disrupting agents in the environment - a review, CLEAN - Soil Air Water 37 (2009) 277-303.

[45] J. Beltran-Heredia, J. Torregrosa, J.R. Dominguez, J.A. Peres, Comparison of the degradation of $p$-hydroxybenzoic acid in aqueous solution by several oxidation processes, Chemosphere 42 (2001) 351-359.

[46] K.S. Tay, N. Abd Rahman, M.R. Bin Abas, Kinetic studies of the degradation of parabens in aqueous solution by ozone oxidation, Environ. Chem. Lett. 8 (2010) 331-337.

[47] Y.P. Gao, T.C. An, H.S. Fang, Y.M. Ji, G.Y. Li, Computational consideration on advanced oxidation degradation of phenolic preservative, methylparaben, in water: mechanisms, kinetics, and toxicity assessments, J. Hazard. Mater. 278 (2014) 417-425.

[48] H.S. Fang, Y.P. Gao, G.Y. Li, J.B. An, P.K. Wong, H.Y. Fu, S.D. Yao, X.P. Nie, T.C. An, Advanced oxidation kinetics and mechanism of preservative propylparaben degradation in aqueous suspension of $\mathrm{TIO}_{2}$ and risk assessment of its degradation products, Environ. Sci. Technol. 47 (2013) 2704-2712.

[49] K.S. Tay, N.A. Rahman, M.R. Abas, Ozonation of parabens in aqueous solution: kinetics and mechanism of degradation, Chemosphere 81 (2010) 1446-1453. 